\title{
Erratum to: Association of molecular markers derived from the BrCRTISO1 gene with prolycopene-enriched orange-colored leaves in Brassica rapa
}

\author{
Seohee Lee $\cdot$ Sang-Choon Lee $\cdot$ Dong Hae Byun $\cdot$ \\ Dong Young Lee $\cdot$ Jee Young Park $\cdot$ Jong Hoon Lee $\cdot$ \\ Hyun Oh Lee $\cdot$ Sang Hyun Sung $\cdot$ Tae-Jin Yang
}

Published online: 30 November 2013

(C) Springer-Verlag Berlin Heidelberg 2013

\section{Erratum to: Theor Appl Genet}

DOI 10.1007/s00122-013-2209-3

In the original version of article, the title was published incorrectly. The correct title should read as "Association of molecular markers derived from the BrCRTISOI gene with prolycopene-enriched orange-colored leaves in Brassica rapa".

The online version of the original article can be found under doi:10.1007/s00122-013-2209-3.

S. Lee $\cdot$ S.-C. Lee $\cdot$ J. Y. Park $\cdot$ J. H. Lee $\cdot$ H. O. Lee

T.-J. Yang $(\bowtie)$

Department of Plant Science, Plant Genomics and Breeding

Institute, and Research Institute for Agriculture and Life

Sciences, College of Agriculture and Life Sciences, Seoul

National University, Seoul 151-921, Republic of Korea

e-mail: tjyang@snu.ac.kr

D. H. Byun

Chinese Cabbage and Breeding Company, Icheon,

Gyeonggi Province 467-842, Republic of Korea

D. Y. Lee $\cdot$ S. H. Sung

College of Pharmacy and Research Institute of Pharmaceutical Science, Seoul National University, Seoul 151-742,

Republic of Korea 